Eur. J. Clin. Chem. Clin. Biochem.

Vol. 30, 1992, pp. $21-25$

(C) 1992 Walter de Gruyter \& Co. Berlin $\cdot$ New York

\title{
The Pattern of Serum Biochemical Abnormalities in Patients with Gallstones
}

\author{
By Abdul Salam Al-Kassab ${ }^{1}$ and Tarek M. S. Malatani ${ }^{2}$ \\ 1 Department of Clinical Biochemistry \\ 2 Department of Surgery College of Medicine, King Saud University, Abha, Saudi Arabia
}

(Received April 16/November 5, 1991)

\begin{abstract}
Summary: The sera from 144 patients ( 27 males and 117 females) with documented gallstones were assayed for eight different biochemical quantities, in order to study the pattern of specific biochemical changes in the blood of such patients and to establish any aetiologic relationship with gallstones. These quantities included: fasting glucose, alkaline phosphatase, alanine aminotransferase, total protein, albumin, total bilirubin, fasting total cholesterol, and fasting triacylglycerol. The same analysis was performed on sera obtained from 50 ( 9 males and 41 females) age- and sex-matched healthy controls. The statistical analysis showed that female patients had significantly higher values for fasting plasma glucose; alkaline phosphatase, total protein and albumin; and significantly lower values for bilirubin and total cholesterol than female controls. No overall differences in the levels of alanine aminotransferase and triacylglycerol were observed between the two female groups. Male patients on the other hand showed significantly higher values for fasting glucose and alkaline phosphatase than male controls. All other quantities, however, were not significantly different between the two male groups. When chemical analysis of the gallstones was performed, no consistent relationship was observed between the level of any of the above mentioned quantities and the chemical subtype of the gallstone (for both male and female patients). These data suggest that no specific serum biochemical pattern characterizes gallstone disease, and that there is no relationship between the stone type and the serum level of the studied quantities.
\end{abstract}

\section{Introduction}

Gallstone disease is a common problem world-wide. Although detailed epidemiological studies are lacking, preliminary observations suggest that it is at least as common in Saudi Arabia as it is in the Western World (1). In our hospital (which is the main referral hospital in the Abha region) around 500 cholecystectomies are performed each year with nearly all of them showing gallstones at operation. While the precise mechanism for gallstone formation remains obscure, certain welldefined associations are recognized (2). In addition, other factors may also play an important aetiological role. These include physical inactivity (leading to obesity), excessive body weight, smoking habits, as well as the patient's race $(3,4)$. Certain medications (e. g. Clofibrate) have also been shown to predispose to gallstone formation (5). Dietary factors have also been implicated $(3,6)$. But in spite of this wealth of observations, it is not fully clear whether gallstone disease is associated with a specific pattern of biochemical abnormalities in serum. Moreover, it is not known whether the chemical composition of the gallstone has any relationship to the level of biochemical quantities in serum. This information could be vital in achieving a better understanding of the pathogenesis of gallstone formation.

The objective of this work was to study the differences in specific biochemical quantities in the sera of patients with gallstones in comparison with normal controls. Any differences would hopefully indicate causal relationships in the process of gallstone formation in our population. Moreover, we analysed the gallstones chemically and classified them according to major subtype. Overall correlations were then sought be- 
tween the stone subtype and the serum biochemistry, in order to gain insight into the formation processes of specific gallstone types.

The serum biochemical quantities chosen included fasting blood glucose (to establish any link between hyperglycaemia and gallstone formation). It also included alanine aminotransferase, alkaline phosphatase, albumin, and total protein (all of which were performed as part of the liver function test package to evaluate liver function in patients with gallstones). Bilirubin and total cholesterol assays were also performed in order to link their serum concentrations to the formation of bilirubin and cholesterol gallstones respectively. Total triacylglycerol was assayed to study any association between gallstone formation and hypertriglyceridaemia.

\section{Patients and Methods}

Patients presenting with gallbladder disease, followed by operation (cholecystectomy) at Asir Central Hospital, Abha, were randomly recruited into this study over a one year period. Only those patients who were subsequently found to have gallstones at operation were included in the study. The selection criteria for the study specifically excluded any patient with a concomitant illness such as diabetes or hypertension (as established from a detailed questioning and thorough physical examination and/or relevant laboratory tests). In addition, none of the patients recruited was receiving any medication prior to hospital admission.

One hundred and fourty four Saudi Arab patients fulfilled the selection criteria and were therefore included in the study. One hundred and seventeen $(77 \%)$ of them were females (female/ male $=4.3: 1)$. The mean overall age of patients was 43.7 years (range 17-98 years). The mean age for females was 42.9 years (range 17-98 years) and for males 47.2 years (range 24-85 years). Thirty seven patients $(26 \%)$ had acute histologically proven cholecystitis. Twenty patients $(14 \%)$ had associated choledocholithiasis.

The control group comprised fifty apparently healthy volunteers (41 were females). They were chosen to match the patient's group for age, sex and dietary habits. The mean overall age for the group was 41.7 years (range 17-62 years). The mean age for the females was 40.1 years (range 17-62) and for males 43.3 years (range 19-54). None of the individuals in this group was receiving any medication and none was known to have any significant illness in the past.

The patients and control group had similar dietary habits. Both groups consumed the traditional Saudi (Arabic) diet comprising wheat bread, rice, and meat (mainly from sheep or goat). Such a diet contained a high concentration (approximately $50 \%$ of dietary calories) of saturated animal fats. None of the patients or the controls was a vegetarian (a dietary practice unknown in this community). Nor were there any smokers in either group (a very rare habit in Southern Saudi Arabia).

Fasting blood samples were obtained after a standard 12 hour overnight fast from both the control group and from patients (in the latter case, one day before the operation). Serum was separated and biochemical assays for glucose, alkaline phosphatase, alanine aminotransferase, total protein, albumin, total bilirubin, total cholesterol and triacylglycerol were performed using a Hitachi 704 chemistry autoanalyzer (Boehringer-Mannheim GmbH, Mannheim, West Germany).
Stones were obtained at operation and were allowed to dry at room temperature for 2 weeks prior to their biochemical assay. They were first weighed then crushed using a mortar and the pulverized stone was assayed qualitatively using an Oxford Medical Systems stone analysis set (Lancer Company, Ireland) The assay for bilirubin in the stone was performed manually according to the method of Jendrassik \& Grof (7) using a commercial kit purchased from Randox Laboratories (N. Ireland). The results of chemical analysis of the stones were reported qualitatively as positive or negative, depending on whether the substance was present or absent. Data was available on stones obtained from 58 patients ( 51 females and 7 males). Stones were classified as "cholesterol stones" if they gave a positive reaction for cholesterol (but negative reaction for bilirubin); there were five stones ( 4 females, 1 male) in this category. Stones which gave a positive reaction to bilirubin (but negative reaction to cholesterol) were considered as "bilirubin stones"; there were fifteen stones in this category ( 12 females, 3 males). Stones giving a positive reaction to both bilirubin and cholesterol were classified as "mixed stones"; there were thirty five stones in this group ( 32 females, 3 males). Only four stones (all in female patients) gave a negative reaction to both bilirubin and cholesterol. Sometimes stones in any of aforementioned groups gave a positive test for some other components such as calcium, ammonium, carbonate and magnesium. These components were not included in the interpretative analysis

\section{Statistical evaluation}

Statistical analysis was performed using an SPSS/PC statistical programme loaded onto a personal computer. Since all of the analytes studied (except cholesterol) had a non-parametric distribution, the Mann-Whithey U test [8] was used in the statistical analysis of the results after calculating the median for each analyte. In the case of cholesterol, the mean and standard deviation were calculated and Student's test was used for comparison

\section{Results}

The results of the analysis of sera obtained from patients and controls are summarized in table 1. Data was obtained separately for males and females in each group and the relevant statistical comparison was performed against the appropriate sex groups in the control. It is evident from the table that female patients with gallstones had significantly higher levels of glucose, alkaline phosphatase, total protein, and albumin. Conversely, these patients had significantly lower values for bilirubin and total cholesterol. No significant differences in the levels of alanine aminotransferase and triacylglycerol were observed. Male patients on the other hand showed a somewhat different overall pattern from those of female patients when compared with male controls. While they also showed significantly higher values for fasting glucose and alkaline phosphatase, no significant differences in the levels of the other analytes were observed.

Table 2 summarizes data of the various biochemical tests in relation to the chemical subgroups of the gallstones (arranged according to the patient's sex). Female patients in all stone subgroups showed similar patterns of results as described in table 1, i. e. signif- 
Tab. 1. Comparison of the concentration of each analyte between the patient group and the control group (divided by sex). Medians (ranges) and $\mathrm{P}$ values are shown

\begin{tabular}{|c|c|c|c|c|c|c|}
\hline \multirow[t]{2}{*}{ Analyte } & \multicolumn{3}{|l|}{ Females } & \multicolumn{3}{|l|}{ Males } \\
\hline & $\begin{array}{l}\text { Patients } \\
\mathrm{N}=117\end{array}$ & $\begin{array}{l}\text { Control } \\
\mathrm{N}=35\end{array}$ & $P$ value & $\begin{array}{l}\text { Patients } \\
\mathrm{N}=27\end{array}$ & $\begin{array}{l}\text { Control } \\
\mathrm{N}=15\end{array}$ & $P$ value \\
\hline $\begin{array}{l}\text { Fasting glucose } \\
(\mathrm{mmol} / \mathrm{l})\end{array}$ & $\begin{array}{l}5.7 \\
(3.4-11.4)\end{array}$ & $\begin{array}{l}4.7 \\
(3.8-6.8)\end{array}$ & $\mathrm{P}<0.0001$ & $\begin{array}{l}6.1 \\
(4.6-10.9)\end{array}$ & $\begin{array}{l}4.9 \\
(3.7-6.9)\end{array}$ & $\mathrm{P}<0.001$ \\
\hline $\begin{array}{l}\text { Alkaline phosphatase } \\
(\mathrm{U} / \mathrm{l})\end{array}$ & $\begin{array}{l}197 \\
(41-1024)\end{array}$ & $\begin{array}{l}144 \\
(72-250)\end{array}$ & $\mathrm{P}<0.0001$ & $\begin{array}{l}228 \\
(50-579)\end{array}$ & $\begin{array}{l}104 \\
(76-213)\end{array}$ & $\mathrm{P}<0.0001$ \\
\hline $\begin{array}{l}\text { Alanine aminotransferase } \\
(\mathrm{U} / \mathrm{l})\end{array}$ & $\begin{array}{l}23 \\
(6-530)\end{array}$ & $\begin{array}{l}22 \\
(17-29)\end{array}$ & $\begin{array}{l}\mathrm{P}>0.05 \\
(\mathrm{NS})\end{array}$ & $\begin{array}{l}33 \\
(13-694)\end{array}$ & $\begin{array}{l}27 \\
(18-39)\end{array}$ & $\begin{array}{l}\mathrm{P}>0.05 \\
(\mathrm{NS})\end{array}$ \\
\hline $\begin{array}{l}\text { Total protein } \\
(\mathrm{g} / \mathrm{l})\end{array}$ & $\begin{array}{l}77 \\
(51-94)\end{array}$ & $\begin{array}{l}68 \\
(63-83)\end{array}$ & $\mathrm{P}<0.001$ & $\begin{array}{l}74 \\
(64-88)\end{array}$ & $\begin{array}{l}73 \\
(65-80)\end{array}$ & $\begin{array}{l}P>0.05 \\
(N S)\end{array}$ \\
\hline $\begin{array}{l}\text { Albumin } \\
(\mathrm{g} / \mathrm{l})\end{array}$ & $\begin{array}{l}44 \\
(24-56)\end{array}$ & $\begin{array}{l}38 \\
(34-42)\end{array}$ & $\mathrm{P}<0.001$ & $\begin{array}{l}42 \\
(32-52)\end{array}$ & $\begin{array}{l}39 \\
(34-42)\end{array}$ & $\begin{array}{l}P>0.05 \\
(\mathrm{NS})\end{array}$ \\
\hline $\begin{array}{l}\text { Bilirubin } \\
(\mu \mathrm{mol} / \mathrm{l})\end{array}$ & $\begin{array}{l}10.3 \\
(3.4-694.0)\end{array}$ & $\begin{array}{l}13.7 \\
(5.1-20.5)\end{array}$ & $P<0.01$ & $\begin{array}{l}14 \\
(3.5-680.0)\end{array}$ & $\begin{array}{l}12 \\
(34-42)\end{array}$ & $\begin{array}{l}P>0.05 \\
(\mathrm{NS})\end{array}$ \\
\hline $\begin{array}{l}\text { Cholesterol* } \\
(\mathrm{mmol} / \mathrm{l})\end{array}$ & $\begin{array}{l}4.6 \\
( \pm 1.2)\end{array}$ & $\begin{array}{l}5.0 \\
( \pm 0.6)\end{array}$ & $\mathrm{P}<0.01$ & $\begin{array}{l}4.9 \\
( \pm 1.2)\end{array}$ & $\begin{array}{l}5.0 \\
( \pm 0.7)\end{array}$ & $\begin{array}{l}P>0.05 \\
(\mathrm{NS})\end{array}$ \\
\hline $\begin{array}{l}\text { Triacylglycerol } \\
(\mathrm{mmol} / \mathrm{l})\end{array}$ & $\begin{array}{l}1.2 \\
(0.3-4.6)\end{array}$ & $\begin{array}{l}1.3 \\
(0.9-1.9)\end{array}$ & $\begin{array}{l}P>0.05 \\
(\mathrm{NS})\end{array}$ & $\begin{array}{l}1.2 \\
(0.6-4.8)\end{array}$ & $\begin{array}{l}1.3 \\
(1.1-2.1)\end{array}$ & $\begin{array}{l}\mathrm{P}>0.05 \\
(\mathrm{NS})\end{array}$ \\
\hline
\end{tabular}

NS $=$ Not Significant

* Since serum cholesterol has a normal distribution, the means ( \pm standard deviation) are given. The statistical comparison was performed by Student's test.

icantly higher results for fasting glucose, alkaline phosphatase, total protein and albumin. No significant differences were observed in the levels of cholesterol and triacylglycerol. Serum alanine aminotransferase levels were significantly higher in female patients with cholesterol stones, but not in other subgroups. Conversely, serum bilirubin was lower in female patients with bilirubin and mixed stones but not in other groups. Male patients on the other hand represented a very small minority in each stone group; thus, any statistical calculation regarding their significance would not be meaningful. This observation equally applies to female patients in the cholesterol subgroup, and in the subgroup of stones which showed no reaction to bilirubin or cholesterol.

\section{Discussion}

Gallstone disease is common all over the world, but unfortunately no clear cause can be recognized. Although the traditional textbook teaching describes its association with some risk factors (female, fertile, forty, fetus, fat) (2) it is by no means clear whether these represent the main causative factors.

In this study we have evaluated the hypothesis that patients with gallstones may show specific biochemical changes in their serum which may be causally related to the formation of gallstones. In addition, we have also studied the relationship between the chem- ical composition of gallstones and biochemical quantities in the serum in order to identify any link with gallstone formation.

Previous work (4) showed no significant correlation between gallstones and diabetes mellitus in a Danish population. Our results supported this by showing that gallstone patients (both males and females) had a median fasting blood glucose within the normal range. However this median was significantly higher (for both sexes) than that of the control group. Although a single measurement of the fasting blood glucose is not enough to confirm the diagnosis of diabetes mellitus or impaired glucose tolerance, it has been suggested that it may be used for screening and giving a crude incidence of diabetes mellitus (9). Thus the observations from our study indicate a need for further detailed work on the pattern of glucose tolerance in patients with gallstones, given that our results showed a high (yet within normal range) fasting blood glucose in the patient group. It is conceivable that people with impaired glucose tolerance (as opposed to diabetic patients) may have a higher incidence of gallstones but this needs to be confirmed by further work.

Scragg et al. (10) examined fasting plasma lipids (total cholesterol and triacylglycerol), and insulin in patients with gallstones. They concluded that increased plasma triacylglycerol was associated with an increased risk of gallstone formation in young subjects. Earlier re- 


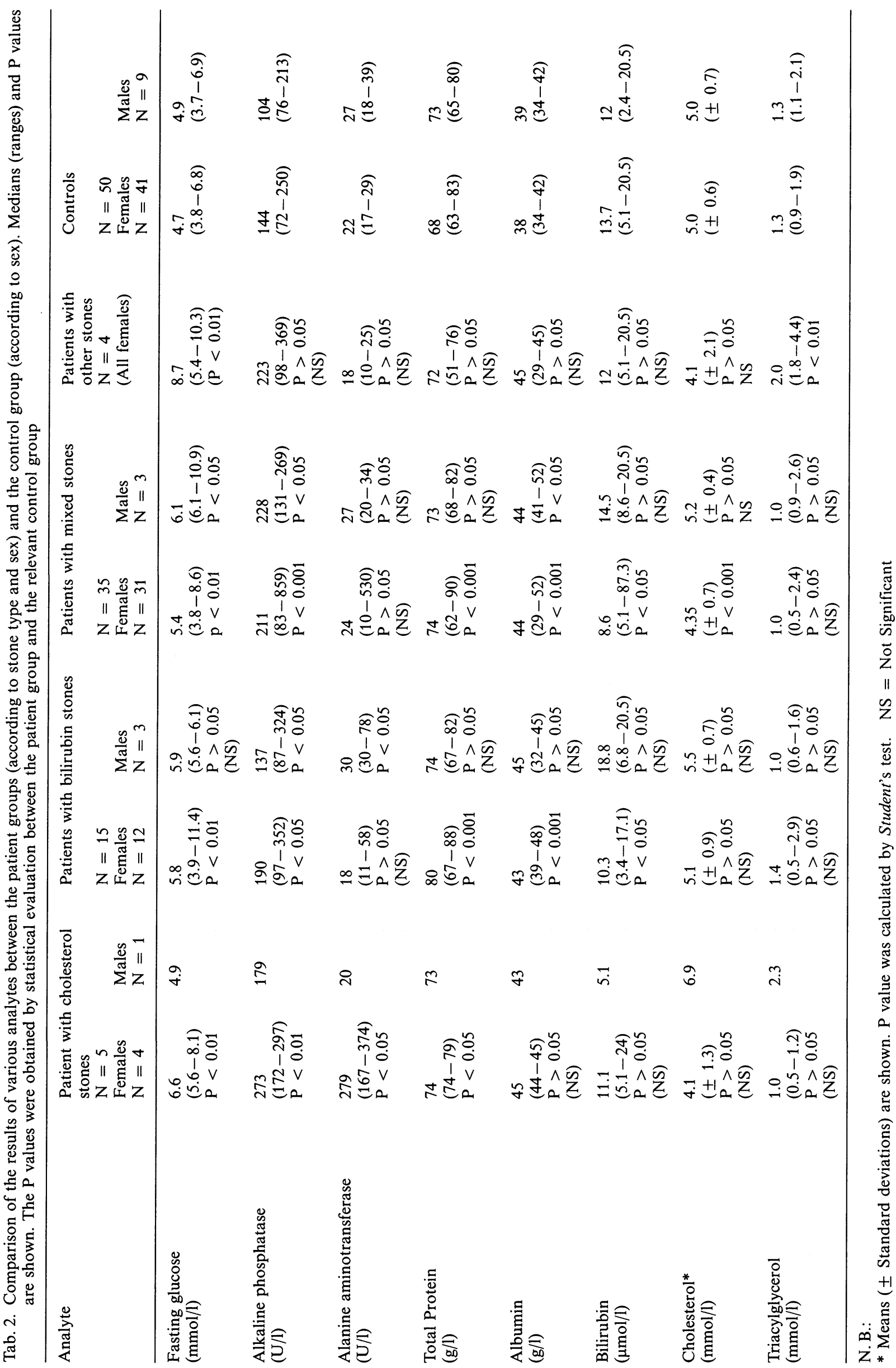


ports $(11,12)$ have supported this observation. Our data did not support these observations, since both the patient group and the control group showed no overall difference in their fasting serum triacylglycerol levels (irrespective of sex). This observation could be due to differences in the ethnic background of our group as well as in the dietary habits, which are similar in both groups and hence may influence the triacylglycerol level in both the patient and the control groups to the same extent. Also, the mean age of our patients (both male and female) was higher than that reported by Scragg et al. The same authors (10), however, observed a negative correlation between serum cholesterol concentration and the risk of stone formation. This was confirmed by our results (for females), since the mean total serum cholesterol concentration was significantly lower in the female patient group than in the control female group.

Measurement of other biochemical quantities revealed significant differences between the patient group and the control group. The serum alkaline phosphatase was significantly higher in the patient group (male and female). Serum alanine aminotransferase on the other hand was not significantly different. These observations may reflect some degree of obstruction by the stones. Serum total protein was significantly higher in female patients, probably indicating an increase in gamma globulin production resulting from the stimulation of the inflammatory response by the presence of the stone. Serum albumin behaved in a similar way. Since this group of tests reflect liver function generally, the differences in their levels between the patient group and the control group cannot be causally related to the process of gallstone formation. Instead, they could reflect the presence of some biliary obstruction known to occur with gallbladder disease. It is interesting to note that the abnormalities are mainly confined to female patients; this may simply reflect the larger proportion of female patients in the sample studied.

Chemical analysis of the stone did not correlate with serum parameters. Of particular note was the fact that patients with cholesterol stones did not show an abnormally high serum cholesterol. Similarly, patients with bilirubin stones did not show abnormally elevated serum bilirubin levels. On the contrary, both groups showed lower values for these 2 analytes than their respective controls. One plausible explanation for these observations may be the presence of an excessive amount of both cholesterol and bilirubin in the lithogenic bile (derived from serum) thus leading to lower values of these substances in serum. An alternative possibility would simply be the complete dissociation between the serum components and biliary components, so that one does not influence the other in any major way.

To the best of our knowledge this is the first study in the literature examining the relationship between the chemical composition of gallstones and changes in serum concentration of several analytes. The number of cases studied was small and obviously further studies involving larger number of patients are needed to confirm these findings.

\section{Acknowledgements}

We would like to thank Mr. Mike dela Paz and Mr. Virgilio A Crisostomo for typing the manuscript and Mr. A. R. Quawasmah for helping in the stone analysis. We also thank Dr. Ahmed Mahfouz for help in the statistical analysis.

\section{References}

1. Mofti, A. B., Al-Tameem, M. M., Al-Khudairy, N. N., Singh, D. N. P. \& Ahmad, I. A. (1987) Experience with elective cholecystectomy in King Khalid University Hospital. Annals of Saudi Medicine 7, 107-110.

2. Watts, J. M., Toouli, J. \& Whiting, M. J. (1987) The formation and dissolution of gallstones. In: Surgery of the Gallbladder and Bile Ducts (Way, L. W. \& Pelligrini, M., eds.) W. B. Saunders Company, Philadelphia, pp. 69-91.

3. Scragg, R. K., McMichael, A. J. \& Baghurst, P. A. (1984) Diet, alcohol and relative weight in gallstone disease: a case control study. Br. Med. J. 288, 1113-1119.

4. Jørgensen, T. (1989) Gallstones in a Danish population Relation to weight, physical activity, smoking, coffee consumption, and diabetes mellitus. Gut 30, 528-534.

5. Greenberger, N. J. \& Isselbacher, K. J. (1991) Diseases of the Gallbladder and Bile Ducts. In: Harrison's Principle of Internal Medicine (Wilson, J. D., Braunwald, E., Isselbacher, K. J., Petersdorf, R. G., Martin, J. B., Fauci, A. S. \& Root, R. K., eds.) 12th edition. McGraw Hill, Inc. New York., p. 1360.

6. Pixley, F. \& Mann, J. (1988) Dietary factors in the aetiology of gallstones: a case control study. Gut 29, 1511-1515.

7. Jendrassik, L. \& Grof, P. (1938) Vereinfachte photometrische Methoden zur Bestimmung des Blutbilirubins. Biochem. Z. 297, $81-86$

8. Armitage, P. (1971) Statistical Methods in Medical Research. Blackwell Scientific publications. Oxford and Edinburgh, pp. $116-126$.

9. World Health Organization (1985) Diabetes mellitus. Report of a study group. Geneva: WHO (WHO Technical Report Series No. 727).

10. Scragg, R. K., Calvert, G. D. \& Oliver, J. R. (1984) Plasma lipids and insulin in gallstone disease: a case control study. Br. Med. J. 289, $521-525$.

11. van der Linden, W. \& Bergman, R. (1977) An analysis of data on human hepatic bile. Relationship between main bile components, serum cholesterol and serum triglycerides. Scand. J. Lab. Invest. 37, $741-747$.

12. Bateson, M. C. (1984) Gallbladder disease and cholecystectomy rate are independently variable. Lancet $i i, 621-$ 624

Dr. A. S. Al-Kassab

College of Medicine

P. O. Box 641

Abha, Saudi Arabia 
